\title{
Impact of Insurance and Hospital Owner- ship on Hospital Length of Stay Among Patients With Ambulatory Care-Sensitive Conditions
}

\author{
Arch G. Mainous III, PbD \\ Vanessa A. Diaz, MD, MS \\ Charles J. Everett, $P b D$ \\ Michele E. Knoll, MA
}

Department of Family Medicine, Medical University of South Carolina, Charleston, South Carolina

Conflicts of interest: authors report none.

\section{CORRESPONDING AUTHOR}

Arch G. Mainous III, PhD

Department of Family Medicine

Medical University of South Carolina

295 Calhoun St

Charleston, SC 29425

mainouag@musc.edu

\begin{abstract}
PURPOSE Some studies suggest proprietary (for-profit) hospitals are maximizing financial margins from patient care by limiting therapies or decreasing length of stay for uninsured patients. This study examines the role of insurance related to length of stay once the patient is in the hospital and risk for mortality, particularly in a for-profit environment.

METHODS We undertook an analysis of hospitalizations in the National Hospital Discharge Survey (NHDS) of the 5-year period of 2003 to 2007 for patients aged 18 to 64 years (unweighted $n=849,866$; weighted $n=90$ million). The analysis included those who were hospitalized with both ambulatory care-sensitive conditions (ACSCS), hospitalizations considered to be preventable, and non-ACSCs. We analyzed the transformed mean length of stay between individuals who had Medicaid or all other insurance types while hospitalized and those who were hospitalized without insurance. This analysis was stratified by hospital ownership. We also examined the relationship between in-hospital mortality and insurance status.
\end{abstract}

RESULTS After controlling for comorbidities; age, sex, and race/ethnicity; and hospitalizations with either an ACSC or non-ACSC diagnosis, patients without insurance tended to have a significantly shorter length of stay. Across all hospital types, the mean length of stay for ACSCs was significantly shorter for individuals without insurance (2.77 days) than for those with either private insurance (2.89 days, $P=.04$ ) or Medicaid (3.19, $P<.01$ ). Among hospitalizations for ACSCs, inhospital mortality rate for individuals with either private insurance or Medicaid was not significantly different from the mortality rate for those without insurance.

CONCLUSIONS Patients without insurance have shorter lengths of stay for both ACSCS and non-ACSCs. Future research should examine whether patients without insurance are being discharged prematurely.

Ann Fam Med 2011;9:489-495. doi:10.1370/afm.1315.

\section{INTRODUCTION}

7 he problem of health care access is one that continues to vex the United States. Recent estimates suggest that in 2009, 46 million US residents younger than 65 years $(17.5 \%)$ were uninsured. ${ }^{1}$ Insurance is an indicator of access to care and is associated with getting timely care for conditions for which appropriate access can make a major difference. Past studies show that patients who do not have health insurance are less likely than those with health insurance to be seen by a physician in ambulatory care for acute conditions. ${ }^{2}$ Health care access, particularly in an ambulatory setting, for such conditions as pneumonia and asthma is important because lack of access leads to increased emergency department use, as well as what could be termed preventable hospitalizations. ${ }^{3-5}$ 
Although the recent passage of the Patient Protection and Affordable Care Act provides health insurance for many more Americans, it is unclear whether other factors affecting the cost of health insurance will actually increase the number of uninsured resulting from the increasing cost of insurance. ${ }^{6-8}$

The number of hospitalizations for patients without insurance in the United States has increased steadily, with a $31 \%$ increase during the last 10 years. This increase is larger than the $13 \%$ seen for overall hospital stays. ${ }^{9}$ There are some data suggesting that lack of insurance is associated with higher mortality risk once hospitalized. ${ }^{10,11}$ There is also concern that for-profit hospitals have an incentive to maximize financial margins from patient care by limiting therapies or decreasing length of stay for uninsured patients. ${ }^{12,13}$ This hypothesis is supported by data that show the mean uninsured stay is $\$ 1,600$ less expensive and shorter (4.0 vs 4.6 days) than a typical hospital stay. ${ }^{9}$ What is unclear is the role of insurance in the delivery of care, or provision of medical care, once the patient is in the hospital for a preventable hospitalization, particularly in a for-profit environment. The purpose of this study was to determine whether lack of health insurance was related to length of stay and risk of mortality for similar diagnoses in a nationally representative sample of hospitalizations in both proprietary and not-for-profit hospitals in the United States.

\section{METHODS}

We conducted an analysis of the National Hospital Discharge Survey (NHDS) of the 5-year period of 2003 to 2007 for patients aged 18 to 64 years. We limited the population to adults of this age-group because most patients aged 65 years and older are insured through Medicare. ${ }^{1,9}$ The NHDS covered 217,252 to 252,737 patients per year in 500 shortstay hospitals by using a stratified, multistage survey to create a nationally representative annual sample of discharge records. Children and general hospitals are included, federal, military, Veterans Affairs, and institutional hospitals are not included. Each discharge record contains up to 7 different International Classification of Diseases, 9th Revision, Clinical Modification (ICD-9-CM) discharge diagnosis codes and is population weighted on the basis of the probability of sample selection and adjusted for nonresponse. Nationally representative estimates of hospitalizations in the United States can be computed with the NHDS. We included all acute-care hospitalizations in the analysis.

There are some data to suggest that uninsured patients leave the hospital against medical advice at a greater rate than those with insurance. ${ }^{9}$ Because dis- charge against medical advice would influence length of stay, we chose to remove patients who left against medical advice from the study. Doing so eliminated 2,522 hospitalizations among those without insurance $(3.4 \%$ of total hospitalizations among uninsured), 4,925 hospitalizations among those on Medicaid (2.1\% of total hospitalizations among those on Medicaid), and 7,026 hospitalizations among those on all other types of insurance $(1.1 \%$ of total hospitalizations among those with all other types of insurance). Thus, by removing persons who were initially hospitalized but were later discharged against medical advice, we eliminated 14,473 of 864,339 hospitalizations, leaving 849,866 unweighted hospitalizations for analysis.

\section{Hospitalizations}

We examined hospitalizations for both ambulatory care-sensitive conditions (ACSC) and non-ACSCs. ACSCs are defined as those conditions for which hospitalizations are thought to be avoidable with the use of preventative care and early disease management, which is usually delivered in the ambulatory setting. ${ }^{5}$ It is thought that proper ambulatory care can help reduce the number of US hospitalizations by preventing, controlling, or managing diseases. Thus, these hospitalizations would be considered preventable hospital visits and would be indicative of a vulnerable population. ${ }^{14}$ Non-ACSCs were included in this study for comparison and to provide context for our analysis of ACSCs.

The Institute of Medicine identified a variety of conditions and affiliated ICD-9-CM codes to represent ACSCs. The following conditions and codes were used: (1) seizures $(345,780.3)_{i}(2)$ severe ear, nose, and throat infections $(382,462,463,465,472.1)_{i}$ (3) chronic obstructive pulmonary disease $(491,492,494$, 496); (4) bacterial pneumonia $(481,482.2,482.3,482.9$, $483,485,486)_{i}(5)$ asthma $(493)_{i}(6)$ congestive heart failure $(428,402.01,402.11,402.91,518.4)_{i}$ (7) hypertension $(401.0,401.9,402.00,402.10,402.90)_{i}(8)$ angina $(411.1,411.8,413) ;(9)$ cellulitis $(681,682,683$, 686); (10) diabetes $(250.0,250.1,250.2,250.3,250.8$, 250.9); (11) hypoglycemia (251.2); (12) gastroenteritis and dehydration $(558.9,276.5)$; and (13) kidney/urinary infection $(590,599.0,599.9)$. Non-ACSCs were primary diagnoses other than those listed above.

For this study, we omitted congenital syphilis, immunization-related conditions, and dental conditions from the Institute of Medicine's list of ACSCs. These conditions had low levels of occurrence as hospitalizations and made estimates unreliable.

For analysis, diagnoses were characterized as an ACSC or non-ACSC based on the primary diagnosis listed. ACSC diagnoses and non-ACSC were examined as categories of diagnoses. 


\section{Outcomes}

Our primary outcome was length of stay for the hospitalization, measured by the NHDS in days. Because length of stay is not normally distributed, we transformed this variable using the natural log to obtain the transformed mean length of stay, which was used for statistical comparisons.

The NHDS reported the discharge disposition, which allowed us to determine whether the hospitalization resulted in a patient death. In terms of death, however, the discharge summary did not specify the cause of death. The diagnoses on the discharge abstract suggested that the disease played a role in patient death.

\section{Health Insurance, Hospital Ownership, Comorbidities, and Other Control Variables}

Health insurance was determined by the primary source of payment collected in the NHDS. We classified individuals with self-pay as being uninsured. Hospital ownership was classified as proprietary or forprofit (operated by individuals, partnerships, or corporations for profit), government (operated by state and local government), and nonprofit (including church).

We used the Deyo-Charlson Comorbidity Index as an indicator of comorbidities. ${ }^{15,16}$ The Deyo-Charlson Comorbidity Index incorporates a patient's history of comorbidities using ICD-9-CM diagnosis codes, with increasing numerical values reflecting greater comorbidity. For each hospitalization, the DeyoCharlson Comorbidity Index was used to generate a score, and hospitalizations were categorized based on scores of 0 through 3 or higher. Because this variable indicates comorbidities, diagnoses were coded based on the nonprimary diagnoses. In other words, a patient with a primary diagnosis of diabetes and no other diagnoses would be given a score of 0 because of the lack of comorbidities. Other control variables were age, sex, and race/ ethnicity.

\section{Analysis}

The NHDS uses a complex survey design that allows the user to make population estimates.
Our analysis used the appropriate sampling weights, and the analysis was conducted using SUDAAN 10.0.1 statistical software to account for the complex sampling designs (SUDAAN, Research Triangle Park, North Carolina).

Our analysis consisted of comparing transformed mean length of stay between individuals who had Medicaid or other insurance for their hospitalization and those without insurance. This comparison was stratified by hospital ownership. For these unadjusted analyses, we performed pairwise contrasts. Next we compared these groups on transformed mean length of stay while adjusting for comorbidities, age, sex and race/ethnicity using a predicted marginal in linear regressions. We examined the relationship between mortality and hospital ownership and insurance status (Medicaid vs all other types of insurance vs uninsured) while controlling for comorbiditites, age, sex, and race/ethnicity in logistic regressions.

\section{RESULTS}

The demographic characteristics of the sample are displayed in Table 1. All estimates are based on the
Table 1. Demographic Characteristics of the Sample

\begin{tabular}{|c|c|c|c|c|c|}
\hline Characteristic & Total & Self-pay & Medicaid & $\begin{array}{l}\text { All Other } \\
\text { Payments }\end{array}$ & $\begin{array}{c}P \\
\text { Value }\end{array}$ \\
\hline Unweighted, $\mathrm{N}$ & 849,866 & 56,760 & 181,285 & 611,821 & \\
\hline Population estimate & $90,221,173$ & $6,663,875$ & $20,271,164$ & $63,286,134$ & \\
\hline \multicolumn{6}{|l|}{ Insurance, \% } \\
\hline Self-pay & 7.4 & & & & \\
\hline Medicaid & 22.5 & & & & \\
\hline All other payments & 70.2 & & & & \\
\hline \multicolumn{6}{|l|}{ Age in years, \% } \\
\hline $18-44$ & 54.5 & 61.3 & 71.3 & 48.5 & \multirow[t]{2}{*}{$<.01$} \\
\hline $45-64$ & 45.5 & 38.7 & 28.7 & 51.5 & \\
\hline \multicolumn{6}{|l|}{ Sex, \% } \\
\hline Male & 36.1 & 49.8 & 25.0 & 38.3 & \multirow[t]{2}{*}{$<.01$} \\
\hline Female & 63.9 & 50.2 & 75.0 & 61.7 & \\
\hline \multicolumn{6}{|l|}{ Race, \% } \\
\hline White & 56.5 & 53.0 & 48.8 & 59.4 & \multirow[t]{3}{*}{$<.01$} \\
\hline Nonwhite & 18.8 & 22.7 & 26.3 & 16.0 & \\
\hline Not stated & 24.7 & 24.3 & 24.8 & 24.7 & \\
\hline \multicolumn{6}{|c|}{$\begin{array}{l}\text { Ambulatory care-sensitive } \\
\text { conditions, } \%\end{array}$} \\
\hline Yes & 12.7 & 17.6 & 11.8 & 12.5 & \multirow[t]{2}{*}{$<.01$} \\
\hline No & 87.3 & 82.4 & 88.2 & 87.5 & \\
\hline \multicolumn{6}{|l|}{ Hospital ownership, \% } \\
\hline Proprietary & 13.3 & 8.9 & 15.2 & 13.1 & \multirow[t]{3}{*}{$<.01$} \\
\hline Government & 12.7 & 24.2 & 17.3 & 10.0 & \\
\hline Nonprofit & 74.0 & 67.0 & 67.5 & 76.9 & \\
\hline \multicolumn{6}{|l|}{ Died in the hospital, \% } \\
\hline Yes & 1.0 & 1.3 & 1.0 & 1.0 & \multirow[t]{2}{*}{.06} \\
\hline No & 99.0 & 98.7 & 99.0 & 99.0 & \\
\hline
\end{tabular}


weighted findings. As is shown in the table, the analysis is based on a weighted sample of more than 90 million hospitalizations. Most hospitalizations included were in nonprofit hospitals (74\% of hospitalizations).

The results indicate in unadjusted analyses a consistent pattern of a shorter length of stay for individuals without insurance (Table 2). This relationship holds for both ACSCs as well as other diagnoses. When nonACSCs are examined in government-owned hospitals, however, the length of stay did not differ between individuals with Medicaid or all other types of insurance and those without insurance.

Table 3 indicates that the pattern of a shorter length of stay for individuals without insurance remains after adjusting for comorbidities, age, sex, and race/ethnicity. Across all hospital types, the length of stay for those without insurance was shorter in the adjusted analysis of ACSCs. ACSCs treated in government hospitals showed no significant difference in length of stay regardless of whether the patient had insurance, other than Medicaid, or was not insured. Looking at adjusted length of stay by type of hospital (Table 4), for-profit hospitals had the longest length of stay for both ACSCs and non-ACSCs.

In terms of in-hospital mortality (Table 5), for all ACSCs adjusted for comorbidities, age, sex, and race/ ethnicity, there was no significant relationship between likelihood of mortality for individuals without insurance compared with those with either Medicaid or other insurance. Because there were relatively few

\section{Table 2. Unadjusted Length of Stay For Patients Aged 18 to 64 Years, by Principal Expected Source} of Payment

\begin{tabular}{|c|c|c|c|c|c|c|}
\hline \multirow[b]{2}{*}{ Hospital Ownership } & \multicolumn{3}{|c|}{ Mean Length of Stay, d } & \multicolumn{3}{|c|}{$P$ Value $^{a}$} \\
\hline & Self-pay & Medicaid & $\begin{array}{l}\text { All Other } \\
\text { Payments }\end{array}$ & $\begin{array}{c}\text { Self-pay } \\
\text { vs Medicaid }\end{array}$ & $\begin{array}{c}\text { Self-pay } \\
\text { vs All Other }\end{array}$ & $\begin{array}{l}\text { Medicaid } \\
\text { vs All Other }\end{array}$ \\
\hline \multicolumn{7}{|l|}{ ACSC } \\
\hline All & 2.61 & 3.19 & 2.89 & $<.01$ & $<.01$ & $<.01$ \\
\hline Proprietary hospital & 2.51 & 3.46 & 3.03 & $<.01$ & .03 & $<.01$ \\
\hline Government hospital & 2.69 & 3.13 & 2.89 & $<.01$ & .01 & .05 \\
\hline Nonprofit hospital & 2.58 & 3.19 & 2.89 & $<.01$ & $<.01$ & $<.01$ \\
\hline \multicolumn{7}{|l|}{ Non-ACSC } \\
\hline All & 2.74 & 2.94 & 2.89 & .02 & $<.01$ & .40 \\
\hline Proprietary hospital & 2.56 & 2.74 & 3.19 & .03 & $<.01$ & $<.01$ \\
\hline Government hospital & 2.94 & 3.00 & 2.94 & .77 & .99 & .75 \\
\hline Nonprofit hospital & 2.72 & 3.00 & 2.83 & $<.01$ & $<.01$ & .04 \\
\hline
\end{tabular}
Table 3. Adjusted Length of Stay for Patients Aged 18 to 64 Years, by Principal Expected Source
of Payment

\begin{tabular}{|c|c|c|c|c|c|c|}
\hline \multirow[b]{2}{*}{ Hospital Ownership } & \multicolumn{3}{|c|}{ Mean Length of Stay, d } & \multicolumn{3}{|c|}{$P$ Value ${ }^{a}$} \\
\hline & Self-pay & Medicaid & $\begin{array}{l}\text { All Other } \\
\text { Payments }\end{array}$ & $\begin{array}{c}\text { Self-pay } \\
\text { vs Medicaid }\end{array}$ & $\begin{array}{c}\text { Self-pay } \\
\text { vs All Other }\end{array}$ & $\begin{array}{l}\text { Medicaid } \\
\text { vs All Other }\end{array}$ \\
\hline \multicolumn{7}{|l|}{ ACSC } \\
\hline All & 2.77 & 3.19 & 2.89 & $<.01$ & .04 & $<.01$ \\
\hline Proprietary hospital & 2.64 & 3.49 & 3.03 & $<.01$ & .09 & $<.01$ \\
\hline Government hospital & 2.83 & 3.06 & 2.83 & .03 & .90 & .06 \\
\hline Nonprofit hospital & 2.77 & 3.16 & 2.86 & $<.01$ & .08 & $<.01$ \\
\hline \multicolumn{7}{|l|}{ Non-ACSC } \\
\hline All & 2.74 & 3.13 & 2.86 & $<.01$ & .01 & $<.01$ \\
\hline Proprietary hospital & 2.64 & 3.03 & 3.19 & $<.01$ & $<.01$ & $<.01$ \\
\hline Government hospital & 2.89 & 3.06 & 2.83 & .16 & .60 & .03 \\
\hline Nonprofit hospital & 2.72 & 3.16 & 2.80 & $<.01$ & .03 & $<.01$ \\
\hline \multicolumn{7}{|c|}{ ACSC = ambulatory care-sensitive condition. } \\
\hline \multicolumn{7}{|c|}{ Note: Adjusted for age, sex, race, and Deyo-Charlson Comorbidity Index. } \\
\hline
\end{tabular}


Table 4. Adjusted Length of Stay For Patients Aged 18 to 64 Years, by Type of Hospital

\begin{tabular}{|c|c|c|c|c|c|c|}
\hline \multirow[b]{2}{*}{ Hospital Ownership } & \multicolumn{3}{|c|}{ Mean Length of Stay, d } & \multicolumn{3}{|c|}{$P$ Value ${ }^{a}$} \\
\hline & $\begin{array}{c}\text { Proprietary } \\
\text { Hospital }\end{array}$ & $\begin{array}{c}\text { Government } \\
\text { Hospital }\end{array}$ & $\begin{array}{c}\text { Nonprofit } \\
\text { Hospital }\end{array}$ & $\begin{array}{c}\text { Proprietary } \\
\text { vs Government }\end{array}$ & $\begin{array}{c}\text { Proprietary } \\
\text { vs Nonprofit }\end{array}$ & $\begin{array}{l}\text { Government } \\
\text { vs Nonprofit }\end{array}$ \\
\hline \multicolumn{7}{|l|}{ ACSC } \\
\hline All & 3.10 & 2.89 & 2.92 & $<.01$ & .02 & .61 \\
\hline Self-pay & 2.64 & 2.83 & 2.77 & .28 & .56 & .49 \\
\hline Medicaid & 3.49 & 3.06 & 3.16 & .04 & .02 & .31 \\
\hline All other payments & 3.03 & 2.83 & 2.86 & .01 & .03 & .59 \\
\hline \multicolumn{7}{|l|}{ Non-ACSC } \\
\hline All & 3.10 & 2.92 & 2.86 & .02 & $<.01$ & .04 \\
\hline Self-pay & 2.64 & 2.89 & 2.72 & .01 & .28 & .03 \\
\hline Medicaid & 3.03 & 3.06 & 3.16 & .61 & .16 & .35 \\
\hline All other payments & 3.19 & 2.83 & 2.80 & $<.01$ & $<.01$ & .12 \\
\hline
\end{tabular}

ACSC = ambulatory care-sensitive condition.

Note: Adjusted for age, sex, race, and Deyo-Charlson Comorbidity Index.

a $P$ value based on difference in days.

Table 5. Adjusted Logistic Regressions for In-Hospital Mortality of Patients Aged 18 to 64 Years, by Principal Expected Source of Payment

\begin{tabular}{|c|c|c|c|}
\hline Hospital Ownership & $\begin{array}{c}\text { Self-pay } \\
\text { OR }(95 \% \mathrm{CI})\end{array}$ & $\begin{array}{c}\text { Medicaid } \\
\text { OR (95\% CI) }\end{array}$ & $\begin{array}{c}\text { All Other Payments } \\
\text { OR }(95 \% \mathrm{CI})\end{array}$ \\
\hline \multicolumn{4}{|l|}{ ACSC } \\
\hline All & $1.00(-)$ & $1.85(0.82-4.19)$ & $1.31(0.67-2.56)$ \\
\hline Proprietary hospitala & $1.00(-)$ & - & - \\
\hline Government hospital ${ }^{\mathrm{a}}$ & $1.00(-)$ & - & - \\
\hline Nonprofit hospital & $1.00(-)$ & $1.01(0.44-2.31)$ & $0.93(0.47-1.83)$ \\
\hline \multicolumn{4}{|l|}{ Non-ACSC } \\
\hline All & $1.00(-)$ & $0.81(0.67-0.98)$ & $0.58(0.50-0.67)$ \\
\hline Proprietary hospital & $1.00(-)$ & $0.68(0.35-1.33)$ & $0.34(0.21-0.54)$ \\
\hline Government hospital & $1.00(-)$ & $0.81(0.60-1.11)$ & $0.83(0.63-1.10)$ \\
\hline Nonprofit hospital & $1.00(-)$ & $0.82(0.65-1.04)$ & $0.59(0.49-0.71)$ \\
\hline
\end{tabular}

$\mathrm{ACSC}=$ ambulatory care-sensitive condition; $\mathrm{OR}=$ odds ratio.

Note: Adjusted for age, sex, race, and Deyo-Charlson Comorbidity Index.

${ }^{a}$ Too few deaths in self-pay group for reliable estimates for Medicaid and all other payments.

\section{DISCUSSION}

Our results based on a nationally representative sample of 5 years of hospitalizations indicate that patients without insurance have shorter lengths of stay than patients with insurance, whether that is government-provided insurance such as Medicaid or other private insurance. This finding is robust and is evident in the vulnerable population of individuals hospitalized with ACSCs even after controlling for comorbidities, age, sex, and race/ethnicity. In terms of in-hospital mortality, patients without insurance are at a higher likelihood of death in both proprietary hospitals and nonprofit hospitals for non-ACSC conditions. No significant difference was seen in mortality for ACSC conditions, although the limited number of deaths for ACSC diagnoses limits this analysis.

Because of the nature of ACSCs, we would expect that individuals who lack access to health care as a result of no insurance would arrive at a hospital with a more severe illness. Instead, our study found that length of stay for patients with ACSC diagnoses was shorter for those without insurance, results similar to those for non-ACSC diagnoses. Previous studies have suggested that hospitalizations for ACSCs are affected by access to health care; individuals who have less access to care resulting from such barriers as socioeconomic status and mistrust of the health care system have longer lengths of stay. These findings were seen 
in individuals with insurance, suggesting that factors other than insurance also can affect access to care and, consequently, hospitalizations. ${ }^{17-19}$ It is unclear why no differences were found between individuals hospitalized with ACSCs and non-ACSCs in this study, but it may be that the lack of insurance is a more robust factor in determining length of stay than, for example, the type of condition or outpatient care received. Our data indicate that in the United States, patients with less access to health care as defined by lack of insurance at admission have shorter lengths of stay, suggesting that either individuals without insurance are not receiving enough care or that individuals with insurance may be receiving more care than needed because it can be billed to the insurance company. This possibility is consistent with previous data showing a lower mean cost for uninsured hospital stays. ${ }^{9}$ Of note, uninsured patients are more likely to leave the hospital against medical advice. ${ }^{9}$ This decision could be spurred by patients' desire to minimize their hospital costs. For our current study, however, we excluded individuals who were discharged against medical advice, eliminating it as a possible explanation for our findings.

Previous research on in-hospital mortality by insurance status has yielded mixed results, which is probably based on the selection of a few specific diagnoses for study. ${ }^{10,20}$ Uninsured patients have tended to have higher in-hospital mortality, which was supported in the current study for non-ACSC diagnoses. The increased mortality rate may be due to a higher initial severity of illness among uninsured individuals or differences in management, such as less use of procedural interventions or interdisciplinary care. ${ }^{10}$ Moreover, the likelihood of in-hospital mortality for patients without insurance was highest in for-profit hospitals. Reasons for these discrepancies are unclear, but it may be that in the for-profit setting differences in management of uninsured patients are magnified.

There are several limitations to this study. First, we could not control for the quality of care delivered in the hospital. It is possible that uninsured individuals are more likely to end up in worse-quality hospitals. With the large number of hospitalizations used in the analysis (more than 127 million) and the nationally representative nature of the data, however, we would expect that insured and uninsured patients would be distributed across hospitals. Recent data on for-profit hospitals treating individuals with myocardial infarction suggested little evidence that for-profit hospitals selectively treat less-sick patients or provide less evidence-based care than nonprofit centers. ${ }^{21}$ Second, it is unclear whether the shorter length of stay found among the uninsured patients represents poor quality of care. We do not have follow-up information on the patients to examine rehospitalizations or other outcomes after discharge. Third, in terms of in-patient mortality, the limited number of deaths in hospitalizations for individuals admitted with ACSCs limited that analysis. Even so, the non-ACSC diagnoses showed the impact of lack of insurance on an increased likelihood of in-hospital mortality.

The problem of providing health insurance to the US population should continue to be a major policy concern. Clinicians should advocate for all patients to be treated equally no matter what type of health insurance or payment type is being provided for services. Uninsured patients have shorter lengths of stay, not only for hospitalizations that should be preventable but for other diagnoses as well. Further, uninsured individuals have an increased likelihood of in-hospital mortality. Addressing the problem of the uninsured with respect to hospital length of stay and in-hospital mortality needs to remain a priority.

To read or post commentaries in response to this article, see it online at http://www.annfammed.org/content/9/6/489.

Key words: Patient-centered care; organizational innovation; patient satisfaction; primary health care; quality of health care

Submitted March 23, 2011; submitted, revised, June 30, 2011; accepted July 8, 2011.

Author contributions: All authors had full access to all of the data in the study and had a role in the writing in the manuscript.

Funding support: Supported in part by a grant from the Duke Endowment.

\section{References}

1. Cohen RA, Martinez ME, Ward BW. Health Insurance Coverage: Early Release of Estimates From the National Health Interview Survey, 2009. National Center for Health Statistics. June 2010. http:// www.cdc.gov/nchs/nhis.htm. Accessed Aug 27, 2010.

2. Parker JD, Schoendorf KC. Variation in hospital discharges for ambulatory care-sensitive conditions among children. Pediatrics. 2000;106(4)(Suppl):942-948.

3. Newton MF, Keirns CC, Cunningham R, Hayward RA, Stanley R. Uninsured adults presenting to US emergency departments: assumptions vs data. JAMA. 2008;300(16):1914-1924.

4. Bindman $A B$, Grumbach $K$, Osmond D, et al. Preventable hospitalizations and access to health care. JAMA. 1995;274(4):305-311.

5. Institute of Medicine. Access to Health Care in America. National Academy Press: Washington, DC; 1993.

6. Berenson RA. Implementing health care reform-why Medicare matters. N Engl J Med. 2010;363(2):101-103.

7. Jennings $\mathrm{CC}$, Hayes $\mathrm{KJ}$. Health insurance reform and the tensions of federalism. N Engl J Med. 2010;362(24):2244-2246.

8. Kaiser Family Foundation. Employer Health Benefits: 2010 Summary of Findings. http://ehbs.kff.org/pdf/2010/8086.pdf. Accessed Sep 7, 2010.

9. Nagamine M, Stocks C, Merrill C. Trends in Uninsured Hospital Stays, 1998-2007. HCUP Statistical Brief \#88. March 2010. Rockville, MD: Agency for Healthcare Research and Quality. http://www.hcup-us. ahrq.gov/reports/statbriefs/sb88.pdf. Accessed Aug 27, 2010. 
10. Hasan O, Orav EJ, Hicks LS. Insurance status and hospital care for myocardial infarction, stroke, and pneumonia. J Hosp Med. 2010;5(8):452-459.

11. Greene WR, Oyetunji TA, Bowers $U$, et al. Insurance status is a potent predictor of outcomes in both blunt and penetrating trauma. Am J Surg. 2010;199(4):554-557.

12. Yuan Z, Cooper GS, Einstadter D, Cebul RD, Rimm AA. The association between hospital type and mortality and length of stay: a study of 16.9 million hospitalized Medicare beneficiaries. Med Care. 2000;38(2):231-245.

13. Sloan FA, Trogdon JG, Curtis LH, Schulman KA. Does the ownership of the admitting hospital make a difference? Outcomes and process of care of Medicare beneficiaries admitted with acute myocardial infarction. Med Care. 2003;41(10):1193-1205.

14. Ansari Z, Barbetti T, Carson NJ, Auckland MJ, Cicuttini F. The Victorian ambulatory care sensitive conditions study: rural and urban perspectives. Soz Praventivmed. 2003;48(1):33-43.

15. Charlson ME, Pompei P, Ales KL, MacKenzie CR. A new method of classifying prognostic comorbidity in longitudinal studies: development and validation. J Chronic Dis. 1987;40(5):373-383.
16. Deyo RA, Cherkin DC, Ciol MA. Adapting a clinical comorbidity index for use with ICD-9-CM administrative databases. J Clin Epidemiol. 1992;45(6):613-619.

17. O'Neil SS, Lake T, Merrill A, Wilson A, Mann DA, Bartnyska LM. Racial disparities in hospitalizations for ambulatory care-sensitive conditions. Am J Prev Med. 2010;38(4):381-388.

18. Iglehart JK. Reform and the health care workforce-current capacity, future demand. N Engl J Med. 2009;361(19):e38.

19. Chen L, Lu HM, Shih SF, Kuo KN, Chen CL, Huang LC. Poverty related risk for potentially preventable hospitalisations among children in Taiwan. BMC Health Serv Res. 2010;10:196.

20. Vidovich MI, Vasaiwala S, Cannon CP, et al; Get With Guidelines Steering Committee and Investigators. Association of insurance status with inpatient treatment for coronary artery disease: findings from the Get With the Guidelines program. Am Heart J. 2010;159(6): 1026-1036.

21. Shah BR, Glickman SW, Liang L, et al. The impact of for-profit hospital status on the care and outcomes of patients with non-STsegment elevation myocardial infarction: results from the CRUSADE Initiative. J Am Coll Cardiol. 2007;50(15):1462-1468.

\section{Get the Annals of Family Medicine by E-mail}

\section{Make sure you see every new issue}

while it's fresh; have the table of

contents sent to you by e-mail for

easy access to articles of interest.

Don't miss important research.

Request the e-mail table of contents at http://lyris.aafp.org/subscribe/annals/.

\section{Close $5^{\circ}$ Reply $\sigma^{\circ}$ Reply All $\Rightarrow$ Forward $\cdot 0 \cdot \theta \Theta \Theta \cdot \mid$ 国国} Mail Properties Personalize Message Source

From: "Annals of Family Medicine" <annalstocelyris.aafp.org> Subject: Annals of Family Medicine Table of Contents

\section{FAMILY MEDICINE}

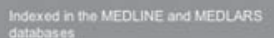

IMUANAFAMMEDORG

ANNOUNCEMENT

The Annals' 2010 impact factor is 4.45 .

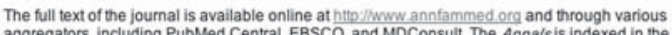
aggregators, including PubMed Central, EBSCO, and MDConsult The Anna/sis indexed in the
MEDLINE and MEDLARS, Science Citation Index Expanded, Current Contents Clinical Medicine, PSycINFO, EMBASE, and CINHAL databases.

EDITORIALS

In This Issue: Technology and Primary Care

Robin S. Gover

Barbara Starfeld: Passage of the Pathinder of Primary Care
Kurt C. Stange The Potential of Sensor-Based Monitoring. as a Tool for Heaith Care. Health Promotion, and Research
Kevin C. Stanley. Nathaniel 0 . Osgood

\section{ORIGINAL RESEARCH}

Consumption of Tea and Coffee and MRSA Nasal Carriage

Enic M. Matheson; Arch G. Mainous III; Charles J. Everelt; Dana E. King

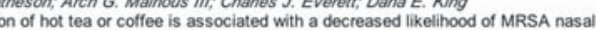
carniage.

Severify of Depression and Magnitude of Productivity LosS

Ame Beck; A. Lauren Crain; Leifl. Solberg: Jürgen Unützer, Russell E. Glasgow; Michael V.

(2) 